\title{
Comparison of Saccharin Time in Nursing Home Residents With and Without Pneumonia: A Preliminary Study
}

\author{
YURIKA UCHIDA $^{1,2^{*}}$, KANJI NOHARA $^{3 *}$, NOBUKAZU TANAKA ${ }^{1}$, NAMI FUJII1, HIKARI FUKATSU ${ }^{1}$, \\ NOBUKO KANEKO ${ }^{4}$, MAKOTO MITSUYAMA $^{5}$ and TAKAYOSHI SAKAI ${ }^{3}$ \\ ${ }^{1}$ Division of Oral-Facial Disorders, Osaka University Dental Hospital, Suita, Japan; \\ ${ }^{2}$ Division of Hospital Dentistry, Okayama University Hospital, Okayama, Japan; \\ ${ }^{3}$ Department of Oral-Facial Disorders, Osaka University Graduate School of Dentistry, Suita, Japan; \\ ${ }^{4}$ Naniwa College of Dental Hygiene, Osaka, Japan; \\ ${ }^{5}$ Medical Corporation Keieikai, Osaka, Japan
}

\begin{abstract}
Background/Aim: Although mucociliary clearance is important for preventing pneumonia, its association with the onset of pneumonia is unclear. The aim of this study is to examine the association between saccharin test results as a potential measure of mucociliary clearance and history of pneumonia in nursing home residents. Patients and Methods: Ninety elderly nursing home residents (elderly group) were selected, 35 of whom had a history of pneumonia. Twenty-five healthy adults (adult group) were also investigated to provide baseline values for this study. We conducted the saccharin test to evaluate mucociliary clearance and compared the saccharin time (ST) between those with and without history of pneumonia. Results: Mean ST in the adult group was $12 \pm 6$ min. The ST in the pneumonia group was significantly longer than that in the non-pneumonia group $(32 \pm 23 \mathrm{~min} v$ s. $17 \pm 13$ min) $(p<0.05)$. Conclusion: Impaired mucociliary clearance is a factor in the development of pneumonia among nursing home residents.
\end{abstract}

Aspiration pneumonia is a major disease caused by dysphagia. It has been reported that aspiration pneumonia accounts for more than $70 \%$ of all cases of pneumonia in the elderly (1). For Japan's super-aged society, preventing aspiration pneumonia and predicting its risk factors are urgent issues.

This article is freely accessible online.

*These Authors contributed equally to this study

Correspondence to: Yurika Uchida, Division of Hospital Dentistry, Okayama University Hospital 2-5-1 Shikata-cho, Kita-ku, Okayama 700-8558, Japan. Tel/Fax: +81 862356588, e-mail: u971587h@alumni.osaka-u.ac.jp

Key Words: Aged, deglutition disorders, mucociliary clearance, nursing home, pneumonia.
Aspiration pneumonia prevention and risk assessment have frequently been examined from the viewpoint of invasion factors, such as bacteria in the oral cavity, aspiration of food or liquid, and esophageal reflux. However, when examining the onset of pneumonia, it is also important to focus on host resistance factors, such as immune function and airway clearance (2). Airway clearance is a mechanism to remove foreign particles inhaled by aspiration from the trachea, and it plays a central role as a host resistance factor. Airway clearance consists of two functions: i) cough clearance and ii) mucociliary clearance. Previous studies $(3,4)$ have found a relationship between pneumonia and cough clearance. Mucociliary clearance is the main defense mechanism of the upper and lower airways. Therefore, in addition to investigating cough clearance, the evaluation of mucociliary clearance is essential for pneumonia prevention and risk prediction.

The saccharin test was firstly described by Andersen $e t a l$. in 1974 (5). It is a useful screening method to evaluate mucociliary clearance by measuring nasal mucociliary transit time, which represents tracheobronchial mucociliary clearance (6). Although the association between saccharin test results and nasal or respiratory diseases has been previously studied (7-9), the association with the development or increased risk of aspiration pneumonia in nursing home residents has not been fully examined. Thus, we hypothesized that impaired mucociliary clearance in nursing home residents is a risk factor for the development of pneumonia. The aim of this study was to examine the association between saccharin test results as a potential measure of mucociliary clearance and history of pneumonia in elderly nursing home residents.

\section{Patients and Methods}

Participants. Elderly residents (elderly group) were recruited from three nursing homes in Osaka that were managed by Medical Corporation Keieikai (Osaka) during 2014-2015. Healthy adults (adult group) who provided the baseline values in this study were recruited from the 
Osaka University Dental Hospital during 2013-2014. Inclusion criteria were the ability to taste and report the sweetness of saccharin. Exclusion criteria included i) acute symptoms of the common cold or respiratory diseases, ii) allergic rhinitis, and iii) current smoker.

Elderly group participants were divided into two sub-groups based on the history of pneumonia over the past year: pneumonia group and non-pneumonia group. We did not characterize further the mechanism of pneumonia as "aspiration". In this study, pneumonia was diagnosed by each participant's primary physician. The criteria for pneumonia diagnosis were: i) a new pulmonary infiltrate seen on a chest radiograph and ii) one of the following features: i) cough, ii) temperature greater than $37.5^{\circ} \mathrm{C}$, or iii) subjective dyspnea (10). Informed consent was obtained from all participants and their families. This study was approved by the ethics committee of the Osaka University Graduate School of Dentistry and Osaka University Dental Hospital (approval number H25-E17).

Saccharin test. The saccharin test (5-9) was conducted in a room at a temperature of $22-25^{\circ} \mathrm{C}$ and humidity level of $30-50 \%$. After entering the room, the participants were instructed to maintain a sitting position for more than $30 \mathrm{~min}$. If there was any excess nasal secretion, it was removed before starting the test.

A 1-mm particle of sodium saccharin (Inoue Seisuke Shoten, Osaka, Japan) was placed $1 \mathrm{~cm}$ behind the right inferior nasal turbinate, under visual control. The time from particle placement until the first perception of a sweet taste (signaling the arrival of the saccharin to the pharynx) was recorded in minutes and recorded as the saccharin time (ST).

During the test, the participants were instructed to maintain their natural breathing and swallowing and not to eat, drink, blow their noses, sniff, sneeze, or cough. The participants were instructed to report as soon as they perceived the sweet taste. At the end of the test, another particle of saccharin was placed directly on their tongue to confirm whether or not they perceived the same taste. If no taste was experienced after $60 \mathrm{~min}$, the ST was treated as $60 \mathrm{~min}$ for statistical analysis.

Statistical analysis. The Mann-Whitney $U$ and chi-square tests were used to determine significant differences in age, sex, clinical dementia rating (CDR) score (11) and history of smoking between the pneumonia and non-pneumonia groups. The Mann-Whitney $U$ test was used to compare the ST between the elderly and adult groups and between the pneumonia and non-pneumonia groups, respectively. The data were expressed as value \pm standard deviation. The level of statistical significance was set at $p<0.05$. All statistical analyses were performed using the Ekuseru-Toukei 2015 software (Social Survey Research Information Co., Ltd., Tokyo, Japan).

\section{Results}

Table I shows the characteristics of the participants. Totally, 90 elderly group participants and 25 adult group participants who met the study criteria were analyzed. The mean CDR score of the elderly group was 1.7 , ranging from 0.5 (questionable) to 3 (severe). In elderly group, 35 participants had a history of pneumonia.

As the baseline value for this study, the mean ST in the adult group was $12 \pm 6 \mathrm{~min}$. The $\mathrm{ST}$ in the elderly group was significantly longer compared to that of the adult group
Table I. Participant characteristics.

\begin{tabular}{lccc}
\hline & $\begin{array}{c}\text { Adult group } \\
(\mathrm{n}=25)\end{array}$ & \multicolumn{2}{c}{ Elderly group $(\mathrm{n}=90)$} \\
\cline { 3 - 4 } & & $\begin{array}{c}\text { Non-pneumonia } \\
\text { group } \\
(\mathrm{n}=55)\end{array}$ & $\begin{array}{c}\text { Pneumonia } \\
\text { group } \\
(\mathrm{n}=35)\end{array}$ \\
\hline Mean age (years) & $29.9 \pm 5.4$ & $82.6 \pm 7.7$ & $83.5 \pm 9.3$ \\
Gender (male/female) & $8 / 17$ & $14 / 41$ & $12 / 23$ \\
Mean CDR (score) & & 1.6 & 1.8 \\
History of smoking & 0 & 12 & 9 \\
\hline
\end{tabular}

CDR: Clinical dementia rating.

$(23 \pm 19 \min v s .12 \pm 6 \mathrm{~min})(p<0.01)$. An ST of $60 \mathrm{~min}$ as the upper limit was not observed in the adult group, but this was observed in 16 participants in the elderly group (Figure 1).

Next, we compared the pneumonia group to the nonpneumonia group. There were no significant differences in age, sex, CDR score and history of smoking (Table I). The $\mathrm{ST}$ in the pneumonia group was significantly longer compared to that of the non-pneumonia group $(32 \pm 23 \mathrm{~min}$ vs. $17 \pm 13 \mathrm{~min})(p<0.05)$. Thirteen participants in the pneumonia group and three in the non-pneumonia group showed an ST of $60 \mathrm{~min}$ as the upper limit (Figure 2).

\section{Discussion}

This study investigated the ST among nursing home residents, and compared mucociliary clearance between those with a history of pneumonia and those without. In the elderly group, the ST was significantly prolonged, and there were also individuals who exceeded the upper time limit. Moreover, comparison based on the history of pneumonia showed that the ST was significantly longer in the pneumonia group compared to the non-pneumonia group.

We used the saccharin test as an index of mucociliary clearance for the purpose of future clinical application in the present study. Nasal mucociliary clearance, measured by this test, is known to have a good correlation with tracheobronchial mucociliary clearance $(5,12)$. In addition, the saccharin test is inexpensive, simple to perform, noninvasive, and reproducible $(5,7,12)$. Although this procedure has already been established, standard STs have yet to be determined. To determine the normal ST for use in this study, we investigated healthy adults. In previous studies, mean STs for healthy adults ranged from 10-15 $\min (6,12)$. The mean ST of $12 \pm 6 \mathrm{~min}$ in the present study is within this range. An ST of $30 \mathrm{~min}$ or shorter was considered normal (13) and STs longer than $60 \mathrm{~min}$ were regarded as markedly prolonged (14). Based on this, STs longer than 60 min observed in the elderly group were considered to indicate markedly impaired mucociliary clearance. These results 


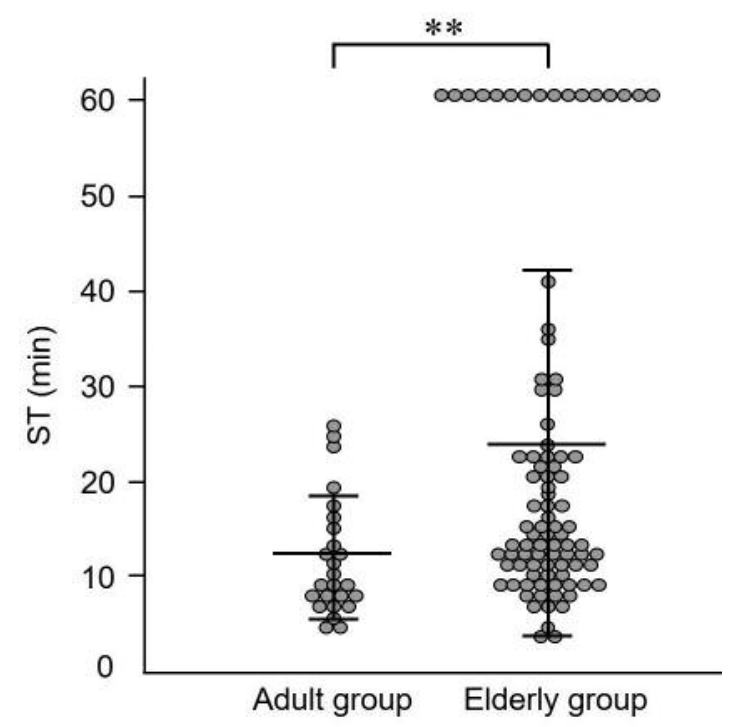

Figure 1. Plots of saccharin time (ST) comparing elderly group and adult group. The ST in the elderly group was significantly longer compared to that of the adult group $\left(*^{*} p<0.01\right)$.

suggest an increased risk of pneumonia due to impaired mucociliary clearance in nursing home residents.

Dehydration (15), history of smoking $(16,17)$, chronic obstructive pulmonary disease (COPD) (18), chronic sinusitis (19), sinobronchial syndrome (20), and gastroesophageal reflux disease (21) have been reported as factors associated with a prolonged ST. While individuals presenting these factors were excluded from the adult group in the present study, those with smoking habits, COPD may have been included in the elderly group. We cannot rule out the possibility that those with chronic sinusitis or slight dehydration may have also been included in the elderly group, although there were no marked clinical findings. Importantly, such factors may be regarded as a characteristic of nursing home residents, and interactions among them may have led to prolongation of ST in the elderly group. To the best of our knowledge, this study is the first to show that there are a certain number of nursing home residents whose ST is markedly prolonged compared to healthy adults.

Assessing the elderly group based on their history of pneumonia, the ST was significantly longer in the pneumonia group compared to the non-pneumonia group. Among the 16 elderly group participants whose ST was 60 min, 13 had a history of pneumonia. These findings suggest that the level of mucociliary clearance influences the development of pneumonia, and the risk of the latter increases when the former decreases. On the other hand, it was difficult to distinguish between pneumonia and aspiration pneumonia in this study, and it was not clear whether impaired mucociliary clearance was directly related

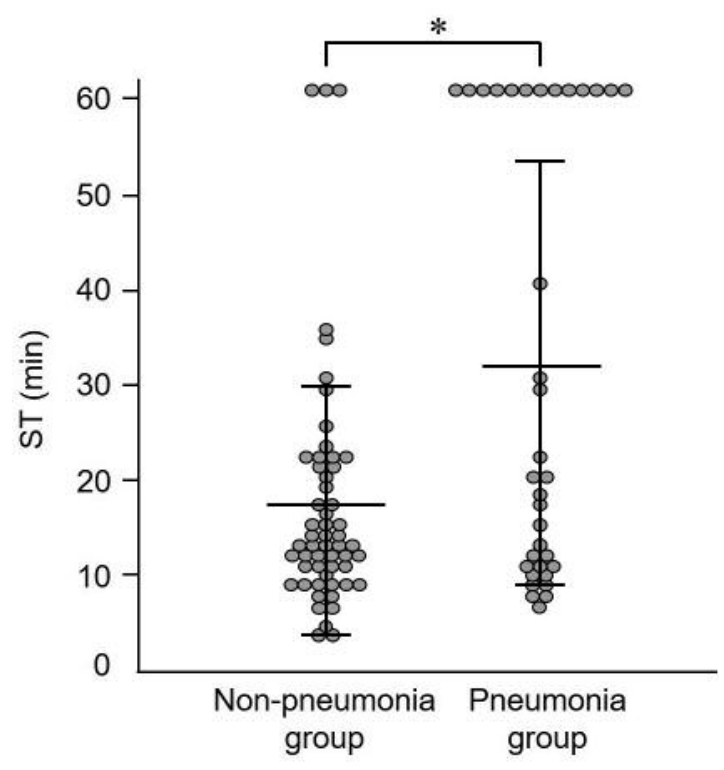

Figure 2. Plots of saccharin time (ST) comparing pneumonia group and non-pneumonia group. The ST in the pneumonia group was significantly longer compared to the non-pneumonia group $\left({ }^{*} p<0.05\right)$.

to aspiration pneumonia. It has been reported that $70 \%$ of all cases of pneumonia in Japanese elderly people are aspiration pneumonia (1); therefore, there may also be an association between mucociliary clearance and aspiration pneumonia.

The present study had some limitations. First, the number of patients was small, thus, further studies with a larger number of patients are required. Second, the availability of data to examine the influence of smoking, COPD, asthma, and dehydration on saccharin test results in detail was limited, as the study targeted nursing home residents with memory impairment and activity limitations for medical reasons. Also, their families did not know the residents' medical or life histories in detail. Third, we did not investigate the possible presence of dysphagia in some elderly participants. Further studies will be conducted, limiting participants to the elderly with aspiration, to continuously examine the association between impaired mucociliary clearance and aspiration pneumonia.

In conclusion, this study suggests that impaired mucociliary clearance is an important factor responsible for the development of pneumonia among nursing home residents. Our study may be of clinical significance by providing background information to help identify individuals with an increased risk of pneumonia and detect impaired mucociliary clearance using the saccharin test.

\section{Conflicts of Interest}

The Authors declare no conflicts of interest in relation to the content of this study. 


\section{Authors' Contributions}

K.N., N.K., M.M. and T.S. designed this study. Y.U., N.T, N.F., H.F. and N.K. collected the data. Y.U. analyzed the data. Y.U. and K.N. drafted the manuscript. All authors contributed to revise the manuscript and approved the final version.

\section{Acknowledgements}

This study was partly supported by JSPS KAKENHI (Project number 24593146, Grant-in-Aid for Scientific Research C).

\section{References}

1 Teramoto S, Fukuchi Y, Sasaki H, Sato K, Sekizawa K, and Matsuse T: High incidence of aspiration pneumonia in community- and hospital-acquired pneumonia in hospitalized patients: a multicenter, prospective study in Japan. J Am Geriatr Soc 56(3): 577-579, 2008. PMID: 18315680. DOI: 10.1111/ j.1532-5415.2008.01597.x

2 Strickland SL, Rubin BK, Drescher GS, Haas CF, O'Malley CA, Volsko TA, Branson RD and Hess DR: AARC clinical practice guideline: effectiveness of nonpharmacologic airway clearance therapies in hospitalized patients. Respir Care 58(12): 21872193, 2013. PMID: 24222709. DOI: 10.4187/respcare.02925

3 Niimi A, Matsumoto H, Ueda T, Takemura M, Suzuki K, Tanaka E, Chin K, Mishima M, Amitani R: Impaired cough reflex in patients with recurrent pneumonia. Thorax 58(2): 152-153, 2003. PMID: 12554900. DOI: 10.1136/thorax.58.2.152

4 Lowery EM, Brubaker AL, Kuhlmann E, and Kovacs EJ: The aging lung. Clin Interv Aging 8: 1489-1496, 2013. PMID: 24235821. DOI: $10.2147 /$ CIA.S51152

5 Andersen I, Camner P, Jensen PL, Philipson K, Proctor DF; A comparison of nasal and tracheobronchial clearance. Arch Environ Health 29(5): 290-293, 1974. PMID: 4472935. DOI: 10.1080/00039896.1974.10666589

6 Plaza Valía P, Carrión Valero F, Marín Pardo J, Bautista Rentero D, and González Monte C: Saccharin test for the study of mucociliary clearance: reference values for a Spanish population. Arch Bronconeumol 44(10): 540-545, 2008. PMID: 19006634.

7 Sauvalle M, Alvo A. Effect of the temperature of nasal lavages on mucociliary clearance: a randomised controlled trial: Eur Arch Otorhinolaryngol 75(9): 2403-2406, 2018. PMID: 30006653. DOI: 10.1007/s00405-018-5060-y

8 Miwa M, Miwa M, Watanabe K. Changes in intramaxillary sinus pressure following antrostomy, draining tubes, and YAMIK procedures in 25 patients treated for chronic paranasal sinusitis: Ear Nose Throat J 90(8): 368-381, 2011. PMID: 21853441. DOI: $10.1177 / 014556131109000810$

9 Pandya VK, and Tiwari RS. Nasal mucociliary clearance in health and disease.: Indian J Otolaryngol Head Neck Surg 58(4): 332-334, 2006. PMID: 23120337. DOI: 10.1007/BF03049581

10 Kikutani T, Tamura F, Tashiro H, Yoshida M, Konishi K, and Hamada R: Relationship between oral bacteria count and pneumonia onset in elderly nursing home residents. Geriatr Gerontol Int 15(4): 417-421, 2015. PMID: 25130073. DOI: $10.1111 /$ ggi.12286
11 Morris JC. Clinical dementia rating: a reliable and valid diagnostic and staging measure for dementia of the Alzheimer type: Int Psychogeriatr 9: 173-176, 1997. PMID: 9447441. DOI: $10.1017 / \mathrm{s} 1041610297004870$

12 Rodrigues F, Freire AP, Uzeloto J, Xavier R, Ito J, Rocha M, Calciolari R, Ramos D, Ramos E: Particularities and clinical applicability of saccharin transit time test. Int Arch Otorhinolaryngol 23(2): 229-240, 2019. PMID: 30956710. DOI: $10.1055 / \mathrm{s}-0038-1676116$

13 Ho JC, Chan KN, Hu WH, Lam WK, Zheng L, Tipoe GL, Sun J, Leung R, Tsang KW: The effect of aging on nasal mucociliary clearance, beat frequency, and ultrastructure of respiratory cilia. Am J Respir Crit Care Med 163(4): 983-988, 2001. PMID: 11282777. DOI: 10.1164/ajrccm.163.4.9909121

14 Canciani M, Barlocco EG, Mastella G, de Santi MM, Gardi C, and Lungarella $\mathrm{G}$ : The saccharin method for testing mucociliary function in patients suspected of having primary ciliary dyskinesia. Pediatr Pulmonol 5(4): 210-214, 1988. PMID: 3237448. DOI: 10.1002/ppul.1950050406

15 Develioglu ON, Sirazi S, Topak M, Purisa S, and Kulekci M: Differences in mucociliary activity of volunteers undergoing Ramadan versus Nineveh fasting. Eur Arch Otorhinolaryngol 270: 1655-1659, 2013. PMID: 23179938. DOI: 10.1007/s00405$012-2277-Z$

16 Xavier RF, Ramos D, Ito JT, Rodrigues FM, Bertolini GN, Macchione M, de Toledo AC, and Ramos EM: Effects of cigarette smoking intensity on the mucociliary clearance of active smokers. Respiration 86(6): 479-485, 2013. PMID: 23615315. DOI: $10.1159 / 000348398$

17 Dülger S, Akdeniz Ö, Solmaz F, Şengören Dikiş Ö, and Yildiz $\mathrm{T}$ : Evaluation of nasal mucociliary clearance using saccharin test in smokers: A prospective study. Clin Respir J 12(4): 1706-1710, 2018. PMID: 29105352. DOI: 10.1111/crj.12733

18 Ito JT, Ramos D, Lima FF, Rodrigues FM, Gomes PR, Moreira GL, Macchione M, Toledo AC, and Ramos EM: Nasal mucociliary clearance in subjects with COPD after smoking cessation. Respir Care 60(3): 399-405, 2015. PMID: 25389352. DOI: $10.4187 /$ respcare 03266

19 Asai K, Haruna S, Otori N, Yanagi K, Fukami M, Moriyama H: Saccharin test of maxillary sinus mucociliary function after endoscopic sinus surgery. Laryngoscope 110(1): 117-122, 2000. PMID: 10646726. DOI: 10.1097/00005537-200001000-00021

20 Tamaoki J, Taira M, Nishimura K, Nakata J, Nagai A: Impairment of airway mucociliary transport in patients with sinobronchial syndrome: role of nitric oxide. J Aerosol Med 13(3): 239-244, 2000. PMID: 11066027. DOI: 10.1089/jam.2000.13.23923.

21 Delehaye E, Dore MP, Bozzo C, Mameli L, Delitala G, and Meloni F: Correlation between nasal mucociliary clearance time and gastroesophageal reflux disease: our experience on 50 patients. Auris Nasus Larynx 36(02): 157-161, 2009. PMID: 18774247. DOI: $10.1016 /$ j.anl.2008.06.004

Received November 25, 2019

Revised December 7, 2019

Accepted December 10, 2019 